\title{
Proposta de avaliação da qualidade de vida e do bem-estar em áreas verdes urbanas
}

\author{
Proposal to assess quality of life and wellbeing in urban \\ green areas
}

Juliana Cláudia Bezerra Campos
José Augusto Ribeiro da Silveira
Geovany Jessé Alexandre da Silva (D)
Eduardo Rodrigues Viana de Lima (iD
Mauro Normando Macêdo Barros Filho iD
Niara Fernandes Barbosa Formiga Dantas

Resumo

$\mathbf{O}$

panorama das problemáticas urbanas evidencia questões

relacionadas à diminuição e ao comprometimento da qualidade de vida nas cidades. Nesse sentido, as áreas verdes são importantes variáveis para a avaliação da qualidade de vida e do bem-estar urbanos. Sob essa ótica, o trabalho objetiva avaliar a qualidade de vida das pessoas a partir da percepção de frequentadores dos dois parques urbanos mais antigos de João Pessoa, PB: o Parque Solon de Lucena (PSL) e o Parque Zoobotânico Arruda Câmara (Pzac). Para isso, foi desenvolvido o índice de bem-estar em áreas verdes (Ibeav), metodologia proposta e adaptada do índice de bem-estar urbano (Ibeu) com indicadores definidos a partir das dimensões mobilidade e acessibilidade, condições ambientais urbanas, condições habitacionais urbanas, serviços coletivos urbanos e infraestrutura urbana. Os resultados obtidos para o Ibeav foram 0,80155 para o PSL e 0,7716 para o Pzac, que indicam boas e médias condições de qualidade de vida, respectivamente. Assim, por meio da metodologia aplicada nos dois parques urbanos, foi possível identificar as dimensões e os indicadores que contribuem para ampliar e/ou reduzir o índice de qualidade de vida de cada espaço avaliado.

Palavras-chave: Qualidade de vida. Áreas verdes. Parque urbano.

${ }^{3}$ Geovany Jessé Alexandre da Silva ${ }^{3}$ Universidade Federal da Paraíba João Pessoa - PB - Brasil

${ }^{4}$ Eduardo Rodrigues Viana de

Lima

${ }^{4}$ Universidade Federal da Paraíba João Pessoa - PB -Brasil

${ }^{5}$ Mauro Normando Macêdo Barros Filho

5Universidade Federal de Campina Campina Grande - PB - Brasil

${ }^{6}$ Niara Fernandes Barbosa Formiga Dantas 6Universidade Federal da Paraíba João Pessoa - PB - Brasil

Recebido em 17/05/20 Aceito em 25/01/21

\section{Abstract}

The current panorama of urban problems highlights issues related to a diminishing and deteriorating quality of life in cities. In this context, green areas are important variables for the evaluation of urban life quality and people, based on the perception of regular users of two urban parks in the city of João Pessoa-PB, northeastern Brazil, the Solon de Lucena Park (PSL) and the Arruda Câmara Zoobotanical Park (Pzac). For this purpose, the authors developed the Wellbeing Index in Green Areas (Ibeav), a methodology proposed and adapted from the Urban Wellbeing Index (Ibeu) with indicators developed from the following dimensions: mobility and accessibility, urban environmental conditions, urban housing conditions, urban collective services and urban infrastructure. The results obtained for the Ibeav were 0.80155 for the PSL and 0.7716 for the Pzac, indicating good and average quality of life conditions, respectively. Hence, through the methodology applied in the two urban parks, it was possible to identify the dimensions and indicators that contribute to expand and/or reduce the quality-of-life index of the evaluated spaces.

Keywords: Quality of life. Indicators. Green areas. Urban park. wellbeing. Hence, the purpose of this study is to evaluate the quality of life of

CAMPOS, J. C. B.; SILVEIRA, J. A. R. da; SILVA, G. J. A. da; LIMA, E. R. V. de; BARROS FILHO, M. N. M.; DANTAS, N. F. B. F. Proposta de avaliação da qualidade de vida e do bem-estar em áreas verdes urbanas. Ambiente Construído, Porto Alegre, v. 21, n. 3, p. 97-115, jul./set. 2021. ISSN 1678-8621 Associação Nacional de Tecnologia do Ambiente Construído. http: //dx.doi.org/10.1590/s1678-86212021000300540 


\section{Introdução}

O panorama das principais problemáticas urbanas atuais evidencia, cada vez mais, questões relacionadas à diminuição e ao comprometimento da qualidade de vida nas cidades. Sob essa ótica, o processo de urbanização e/ou expansão das cidades, intensificado principalmente durante o período industrial, contribuiu para a diminuição paulatina da qualidade de vida e do bem-estar das pessoas, em específico nos espaços mais urbanizados.

Nesse contexto, a partir do crescente destaque sobre conceitos como "qualidade ambiental" e "qualidade de vida", cada vez mais estudos (FARQUHAR, 1995; NAHAS et al., 2006) são direcionados com o intuito de associar elementos presentes no espaço urbano com a melhoria da qualidade de vida e do bem-estar das pessoas. Pesquisas sobre a temática evidenciam os diferentes enfoques em relação aos principais aspectos conceituais de qualidade de vida e do bem-estar urbano. Nesse escopo, destacam-se trabalhos como o de Seidl e Zannon (2004), que enfatiza a temática como algo observado ainda em décadas passadas, e o de Nahas et al. (2006), que destacou o surgimento dessas discussões diante de problemas provenientes principalmente do processo de urbanização.

Por outro lado, as áreas verdes livres são espaços importantes da cidade e podem ser consideradas variáveis potenciais de impacto no ambiente, estando cada vez mais associadas à qualidade urbana nas cidades e, portanto, podendo ser analisadas e observadas como indicadores para a avaliação da qualidade de vida e do bem-estar das pessoas. Pesquisas como a de Chen, Xua e Gao (2015), que ressalta as áreas verdes livres como espaços que potencializam melhor qualidade de vida e bem-estar das pessoas, também evidenciam a relevância e a influência desses espaços dentro do ambiente urbano. Entretanto, também existem questionamentos quanto à falta de uso ou à subutilização desses espaços, que, por vezes, são relacionados a lugares inseguros, maltratados, segregados e/ou marginalizados. Tais impressões ainda são fortalecidas quando se observa um número crescente de pessoas em espaços privados, como grandes centros comerciais ou outros ambientes, em detrimento das que frequentam espaços livres públicos, como os parques urbanos.

Contudo, ainda que se reconheçam as áreas verdes como elementos potenciais dentro da urbe, percebe-se, ainda, insuficiência de métodos que buscam avaliar a qualidade de vida e o bem-estar das pessoas no espaço urbano, em especial nos casos urbanos brasileiros. Sabe-se que, historicamente, os índices que avaliam a qualidade de vida e o bem-estar das pessoas utilizam, majoritariamente, indicadores sociais e econômicos, não reconhecendo, para isso, indicadores naturais, espaciais ou ambientais como as áreas verdes livres, por exemplo. Metodologias e/ou ferramentas que têm como objetivo avaliar a qualidade de vida e o bem-estar urbano são abrangentes e, em geral, não utilizam indicadores específicos como as áreas verdes livres, exemplo disso são o Mercer's Quality of Living Ranking (Quality of Living Index) (MERCER ${ }^{1}$ ), o Numbeo, banco de dados de contribuição sobre as condições de vida em cidades e países em todo o mundo $\left(\mathrm{NUMBEO}^{2}\right.$ ), o Monocle's Quality of Life Survey (KAKLAUSKAS et al., 2018), o índice de qualidade de vida urbana (IQVU/MS) (FIGUEIREDO, 2008) e o próprio índice de bem-estar urbano (Ibeu) (RIBEIRO; RIBEIRO, 2013). Destaca-se, portanto, a necessidade de modelos que possam investigar a influência desses elementos, as áreas verdes livres como os parques urbanos, por exemplo, na qualidade de vida e no bemestar das pessoas.

A partir desse contexto, o trabalho objetiva investigar a influência das áreas verdes urbanas na qualidade de vida e no bem-estar das pessoas nas cidades. Nesse sentido, é feita uma análise da percepção de usuários em dois parques urbanos antigos de João Pessoa, PB: o Parque Solon de Lucena (PSL) e o Parque Zoobotânico Arruda Câmara (Pzac). A metodologia analítica utilizada na pesquisa, que desenvolveu e aplicou o índice de bem-estar em áreas verdes (Ibeav), é proposta a partir da adaptação do índice de bem-estar urbano (Ibeu) ${ }^{3}$, amplamente utilizado pelo Observatório das Metrópoles no Brasil. Este índice, composto de 21 indicadores, é distribuído em cinco dimensões: mobilidade e acessibilidade, condições ambientais urbanas, condições habitacionais urbanas, serviços coletivos urbanos e infraestrutura urbana. Para a composição do Ibeav também foram considerados indicadores subjetivos, como, por exemplo, sensações de felicidade e de bemestar dos usuários, pois constituem variáveis tão importantes quanto os indicadores objetivos, definidos por dados econômicos e/ou sociais.

${ }^{1}$ Mercer Human Resource Consulting é uma empresa fundada por William Manson Mercer e subsidiária da Marsh \& McLennan Companies. Disponível em: https://mobilityexchange.mercer.com/insights/quality-of-living-rankings.

${ }^{2}$ Numbeo é um banco de dados global de estatísticas relacionadas à qualidade de vida, indicadores de habitação etc. Disponível em: https: //www.numbeo.com/common/.

${ }^{3}$ Disponível em: https://ibeu.observatoriodasmetropoles.net.br/. Acesso em: 19 out. 2020. 


\section{Qualidade de vida: principais aspectos conceituais}

Segundo Seidl e Zannon (2004), o termo "qualidade de vida" surgiu na década de 1930, mas somente após 1960 foram observadas questões mais específicas sobre o termo. Entretanto, apenas na década de 1970 surgem discussões sobre a temática, principalmente a partir de problemas sociais e ambientais provenientes do processo de urbanização e expansão urbana (NAHAS et al., 2006). De modo mais amplo, Farquhar (1995) apresenta uma revisão em que propõe uma taxonomia para o termo "qualidade de vida", apresentada no Quadro 1.

Para Nahas et al. (2006), o termo "qualidade de vida" está associado aos conceitos de bem-estar, qualidade ambiental, pobreza, desigualdades sociais, exclusão social, vulnerabilidade social, desenvolvimento sustentável e sustentabilidade.

Segundo Herculano (2000), a qualidade de vida também pode ser observada a partir de aspectos como proporção de áreas verdes e espaços abertos urbanos disponíveis. Szeremeta e Zannin (2013) avaliaram a influência desses espaços, dando ênfase aos fatores sociais e ambientais, os resultados mostraram benefícios sociais, físicos e psicológicos da comunidade usuária. Já Silva (2014) investigou as relações entre áreas verdes urbanas e qualidade de vida a partir de frequentadores de parques urbanos em Vila Real, Portugal. Neste caso, o estudo apontou para espaços que intensificam as relações sociais ao mesmo tempo em que atuam, favoravelmente, nos estados físico, emocional e psíquico dos indivíduos.

Desenvolvido na Europa entre 2012 e 2016, um estudo sobre a análise de metodologias que avaliam a sustentabilidade urbana e a qualidade de vida a partir de indicadores quali-quantitativos sugere uma adaptação do método Invar (análise de critérios múltiplos da qualidade da cidade) (KAKLAUSKAS et al., 2018) a fim de otimizar o Quality of Life Index (QLI) (CONGER, 2015).

\section{Quadro 1 - Taxonomia das definições de qualidade de vida segundo Farquhar}

\begin{tabular}{|l|l|}
\hline \multicolumn{1}{|c|}{ Taxonomia } & \multicolumn{1}{c|}{ Características das definições } \\
\hline I - Definição global & $\begin{array}{l}\text { Primeiras definições de qualidade de vida até meados da } \\
\text { década de 1980. Não abordam dimensões, avaliam apenas } \\
\text { satisfação/insatisfação da vida. }\end{array}$ \\
\hline II - Definição com base em componentes & $\begin{array}{l}\text { Baseadas em componentes a partir de 1980, inicia-se o } \\
\text { fracionamento do conceito global em } \\
\text { componentes/dimensões. Destaque para estudos empíricos e } \\
\text { operacionalização do conceito. }\end{array}$ \\
\hline III - Definição focalizada & $\begin{array}{l}\text { Valoriza componentes específicos, voltados para } \\
\text { habilidades funcionais ou de saúde. Relacionam qualidade } \\
\text { de vida à saúde com ênfase aos aspectos empíricos e } \\
\text { operacionais. Instrumentos que avaliam a qualidade de vida } \\
\text { são desenvolvidos. }\end{array}$ \\
\hline IV - Definição combinada & $\begin{array}{l}\text { Definiços incorporam aspectos dos Tipos II e III: } \\
\text { favorecem aspectos do conceito em termos globais e } \\
\text { abrangem dimensões com ênfase empírica e operacional. } \\
\text { Instrumentos de avaliação global e fatorial são } \\
\text { desenvolvidos. }\end{array}$ \\
\hline
\end{tabular}

Fonte: adaptado de Farquhar (1995). 


\section{Índices de qualidade de vida}

Considerando o contexto internacional, os índices da Mercer Mobility Management Platform (MMP) sobre classificação da qualidade de vida da cidade (MERCER..., 2018), o banco de dados do Numbeo, já citado, (NUMBEO, 2018) e Monocle (KAKLAUSKAS et al., 2018) destacam-se como ferramentas que avaliam a qualidade de vida a partir de indicadores políticos, sociais, econômicos e ambientais. Por outro lado, dentro do cenário nacional, ressalta-se como uma das maneiras mais tradicionais de avaliar a qualidade de vida a utilização do índice de desenvolvimento humano (IDH) (PROGRAMA..., 2014) e do coeficiente de desigualdade Gini (BANCO MUNDIAL, 2020), como dois dos principais indicadores mundiais nessa abordagem. Nesse contexto, é possível destacar os seguintes índices:

(a) Índice de Qualidade de Vida Urbana de João Pessoa (IQVU/JP) (LIRA et al., 2017), desenvolvido para o município, que analisa aspectos como facilidades, acessibilidade e amenidades urbanas e, de modo geral, apresenta quatro dimensões compostas de indicadores tratados de modo ponderado, que são: indicador de qualidade habitacional (Iqhab), indicador de facilidades urbanas (Iqfa), indicador de acessibilidades urbanas (Iace) e indicador de ambiência urbana (Iqam);

(b) Índice de Qualidade de Vida Urbana (IQVU/MS), desenvolvido a partir de parâmetros de pesquisas e dados do Censo Demográfico do Instituto Brasileiro de Geografia e Estatística (BGE), que, segundo Figueiredo (2008), objetiva normalizar indicadores preexistentes para um cenário comparativo entre bairros e aplicação em áreas menores;

(c) Índice de Qualidade de Vida Urbana (IQVU/BH), que destaca os indicadores:

- possibilidade de quantificar e qualificar os bens e os serviços públicos e privados disponíveis para a população;

- rápida atualização das variáveis em curtos períodos de tempo; e

- utilização de informações disponíveis pelos órgãos públicos.

(d) Índice de Qualidade de Vida Urbana dos municípios brasileiros (IQVU/BR), desenvolvido pelo Ministério das Cidades e pelo Instituto de Desenvolvimento Humano Sustentável da Pontifícia Universidade Católica de Minas Gerais (IDHS/PUC Minas-Belo Horizonte/MG) por meio do Programa das Nações Unidas para o Desenvolvimento (PNUD) (NAHAS et al., 2006); e

(e) Índice de bem-estar urbano (Ibeu), desenvolvido a partir da Pesquisa Nacional por Amostra de Domicílios (Pnad), é utilizado pelo Observatório das Metrópoles e, atualmente, utiliza dados do IBGE e divide-se em global e local. O primeiro considera um conjunto de 15 metrópoles e compara condições urbanas nas escalas metropolitana, municipal e de bairros. Já o segundo avalia as características intraurbanas específicas de cada cidade (RIBEIRO; RIBEIRO, 2013). A síntese das dimensões e dos indicadores presentes nos índices de qualidade de vida e de bem-estar urbanos, destacados no Quadro 2, evidencia significativa diversidade de parâmetros utilizados.

Entretanto, a síntese anterior também evidencia a falta de indicadores urbanos, como áreas verdes livres, assim como indicadores subjetivos, como níveis de satisfação e felicidade. Por outro lado, percebe-se a presença de apenas um indicador relacionado a elementos naturais presentes na urbe, o meio ambiente urbano, presente em três índices selecionados. Ainda assim, destacam-se indicadores comumente utilizados para avaliar qualidade de vida e bem estar como habitação/moradia, educação, abastecimento de água, saúde e serviços urbanos. 
Quadro 2 - Índices de qualidade de vida e de bem-estar, dimensões e indicadores

\begin{tabular}{|c|c|c|c|c|c|c|c|}
\hline \multirow[b]{2}{*}{$\begin{array}{l}\text { Dimensão/ } \\
\text { Indicadores }\end{array}$} & \multicolumn{7}{|c|}{ Índice de qualidade de vida e de bem-estar } \\
\hline & $\begin{array}{c}\text { Ibeu } \\
\text { Ribeiro e } \\
\text { Ribeiro } \\
\text { (2013) }\end{array}$ & $\begin{array}{c}\text { IQVU/MS } \\
\text { Figueiredo } \\
\text { (2008) }\end{array}$ & $\begin{array}{c}\text { IQVU/ } \\
\text { JP } \\
\text { Lira } e t \\
\text { al. } \\
(2017) \\
\end{array}$ & $\begin{array}{c}\text { IQVU/ } \\
\text { BH } \\
\text { PMBH } \\
(2019)\end{array}$ & $\begin{array}{c}\text { IQVU/ } \\
\text { BR } \\
\text { Nahas } \\
\text { et al. } \\
\text { (2006) } \\
\end{array}$ & $\begin{array}{c}\text { IQV/ } \\
\text { Mercer } \\
\text { Kaklauskas } \\
\text { et al. (2018) }\end{array}$ & Total \\
\hline $\begin{array}{l}\text { Abastecimento de } \\
\text { água }\end{array}$ & $\mathrm{X}$ & & $\mathrm{X}$ & $\mathrm{X}$ & & & $\mathrm{XXX}$ \\
\hline Ambiente econômico & & & & & & $\mathrm{X}$ & $\mathrm{X}$ \\
\hline Ambiente natural & & & & & & $\mathrm{X}$ & $\mathrm{X}$ \\
\hline $\begin{array}{l}\text { Ambiente político e } \\
\text { social }\end{array}$ & & & & & & $\mathrm{X}$ & $\mathrm{X}$ \\
\hline $\begin{array}{l}\text { Ambiente } \\
\text { sociocultural }\end{array}$ & & & & & & $\mathrm{X}$ & $\mathrm{X}$ \\
\hline Bens de consumo & & & & & & $\mathrm{X}$ & $\mathrm{X}$ \\
\hline Comércio e serviços & & & & & $\mathrm{X}$ & & $\mathrm{X}$ \\
\hline $\begin{array}{l}\text { Condições ambientais } \\
\text { urbanas }\end{array}$ & $\mathrm{X}$ & & & & & & $\mathrm{X}$ \\
\hline $\begin{array}{l}\text { Condições } \\
\text { habitacionais urbanas }\end{array}$ & $\mathrm{X}$ & & & & & & $\mathrm{X}$ \\
\hline $\begin{array}{l}\text { Condições de serviços } \\
\text { coletivos urbanos }\end{array}$ & $\mathrm{X}$ & & $\mathrm{X}$ & & & & $\mathrm{XX}$ \\
\hline $\begin{array}{l}\text { Considerações } \\
\text { médicas e de saúde }\end{array}$ & & & & & & $\mathrm{X}$ & $\mathrm{X}$ \\
\hline Cultura & & & & $\mathrm{X}$ & $\mathrm{X}$ & & $\mathrm{XX}$ \\
\hline Economia & & & & & $\mathrm{X}$ & & $\mathrm{X}$ \\
\hline Educação & & $\mathrm{X}$ & $\mathrm{X}$ & $\mathrm{X}$ & $\mathrm{X}$ & & XXXX \\
\hline Escolas e educação & & & & & & $\mathrm{X}$ & $\mathrm{X}$ \\
\hline Esgoto sanitário & $\mathrm{X}$ & & & & & & $\mathrm{X}$ \\
\hline Esporte & & & & $\mathrm{X}$ & & & $\mathrm{X}$ \\
\hline Habitação/Moradia & $\mathrm{X}$ & $\mathrm{X}$ & $\mathrm{X}$ & $\mathrm{X}$ & $\mathrm{X}$ & $\mathrm{X}$ & $\begin{array}{c}\text { XXXXX } \\
\text { X }\end{array}$ \\
\hline Infraestrutura urbana & $\mathrm{X}$ & & & $\mathrm{X}$ & & & $\mathrm{XX}$ \\
\hline $\begin{array}{l}\text { Instrumentos de gestão } \\
\text { urbanística }\end{array}$ & & & & & $\mathrm{X}$ & & $\mathrm{X}$ \\
\hline Lazer & & & $\mathrm{X}$ & & & & $\mathrm{X}$ \\
\hline Meio ambiente urbano & & & $\mathrm{X}$ & $\mathrm{X}$ & $\mathrm{X}$ & & $\mathrm{XXX}$ \\
\hline Mobilidade urbana & $\mathrm{X}$ & & & & & & $\mathrm{X}$ \\
\hline $\begin{array}{l}\text { Participação e } \\
\text { organização } \\
\text { sociopolítica }\end{array}$ & & & & & $\mathrm{X}$ & & $\mathrm{X}$ \\
\hline Recreação & & & & & & $\mathrm{X}$ & $\mathrm{X}$ \\
\hline Renda e pobreza & & $\mathrm{X}$ & & & & & $\mathrm{X}$ \\
\hline Resíduos sólidos & $\mathrm{X}$ & & & & & & $\mathrm{X}$ \\
\hline Saúde & & & $\mathrm{X}$ & $\mathrm{X}$ & $\mathrm{X}$ & & $\mathrm{XXX}$ \\
\hline Segurança pública & & & & & $\mathrm{X}$ & & $\mathrm{X}$ \\
\hline Serviços de segurança & & & & $\mathrm{X}$ & & & $\mathrm{X}$ \\
\hline Serviços urbanos & $\mathrm{X}$ & & $\mathrm{X}$ & $\mathrm{X}$ & & & XXX \\
\hline $\begin{array}{l}\text { Serviços e transporte } \\
\text { público }\end{array}$ & & & $\mathrm{X}$ & & & $\mathrm{X}$ & $\mathrm{XX}$ \\
\hline Socioeconômico & & & & & $\mathrm{X}$ & & $\mathrm{X}$ \\
\hline $\begin{array}{l}\text { Sustentabilidade } \\
\text { ambiental }\end{array}$ & & $\mathrm{X}$ & & & & & $\mathrm{X}$ \\
\hline Transportes & & & $\mathrm{X}$ & & $\mathrm{X}$ & & $\mathrm{XX}$ \\
\hline
\end{tabular}




\section{Método}

Para investigar a influência das áreas verdes urbanas na qualidade de vida e no bem-estar em parques urbanos, a pesquisa foi desenvolvida em cinco etapas metodológicas, quais sejam:

(a) etapa 1 - pesquisa exploratória com base nas referências bibliográficas sobre os temas qualidade de vida, índices de qualidade de vida e áreas verdes com o objetivo de identificar definições, questões associadas à qualidade de vida, indicadores e ferramentas metodológicas utilizadas;

(b) etapa 2 - definição dos indicadores objetivos e subjetivos do Ibeav, sua estruturação, organização e composição, adaptados a partir do Ibeu (RIBEIRO; RIBEIRO, 2013);

(c) etapa 3 - elaboração do questionário, estruturado a partir de objetivos predefinidos e dos indicadores do Ibeav;

(d) etapa 4 - definição do universo da pesquisa e do tamanho da amostra, e aplicação dos questionários em dois parques urbanos de João Pessoa; e

(e) etapa 5 - tabulação, análise e tratamento dos dados e apresentação dos resultados.

Todas as etapas seguem a sequência lógica apresentada na Figura 1.

\section{Definição dos indicadores do Ibeav}

A proposição do Ibeav, desenvolvido a partir de adaptação do Ibeu, foi definida com base em indicadores subjetivos relacionados ao nível de felicidade, bem-estar e saúde, além de indicadores objetivos, que abrangem as condições de moradia e de serviços.

Assim, os indicadores subjetivos definidos foram condições de deslocamento (CD), bem-estar e saúde (BS), clima e conforto (CC), relação áreas verdes e qualidade de vida (AQ), qualidade de vida durante a permanência no parque (QD), qualidade de vida depois da permanência no parque (QP) e satisfação/felicidade (SF). Já os indicadores objetivos consideraram tempo de deslocamento (TD), arborização no entorno da residência (AE), poluição no entorno da residência (PE), calçada (CÇ), densidade de banheiro (DB), densidade domiciliar (DD), energia (EG), atendimento de água (AG), atendimento de esgoto (AE), coleta de resíduos (CR), iluminação pública (IP), logradouro (LG), pavimentação (PV) e rampa de acessibilidade (RP). A estrutura do Ibeav, apresentada no Quadro 3, baseou-se, sobretudo, na composição do Ibeu.

Vale destacar que os critérios para a escolha dos indicadores objetivos, como condições habitacionais urbanas e serviços coletivos urbanos, foram definidos em relação aos mesmos indicadores que compõem o Ibeu. Por outro lado, a definição dos indicadores subjetivos se deu, prioritariamente, pelo fato de que se entende que, para mensurar a qualidade de vida e o bem-estar das pessoas, indicadores como felicidade, conforto, saúde e bem-estar, por exemplo, também devem compor ferramentas que desenvolvam tais avaliações.

Desse modo, o Ibeav se apresenta a partir da estrutura geral exibida na Figura 2.

Figura 1 - Diagrama das etapas da pesquisa

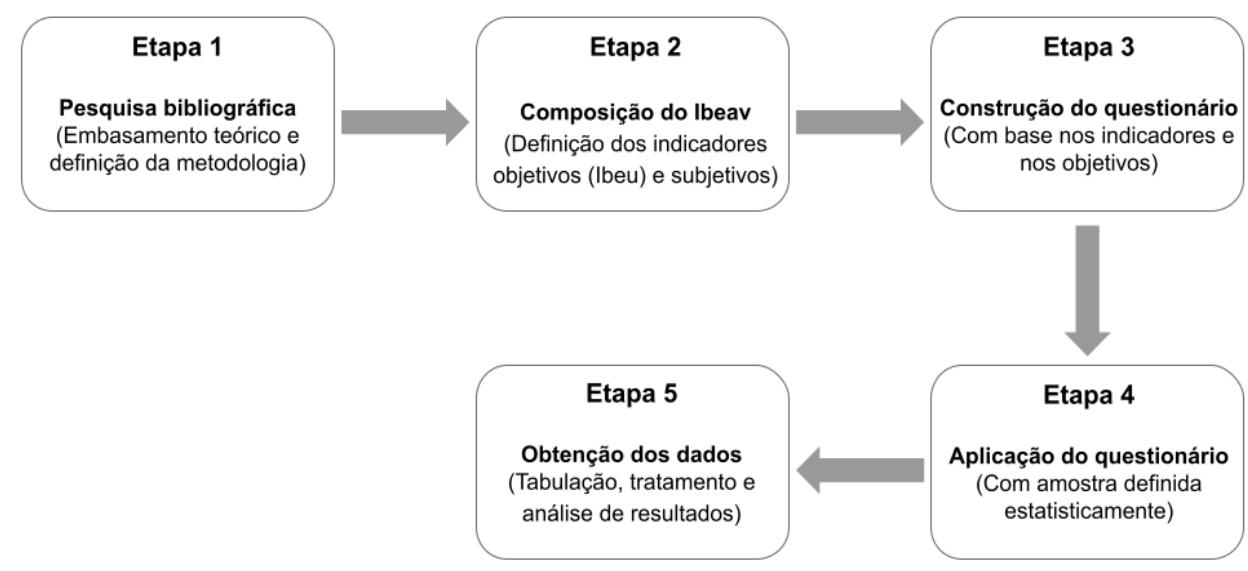


Quadro 3 - Dimensões, indicadores e respectivos pesos do Ibeav

\begin{tabular}{|c|c|c|c|}
\hline \multirow{2}{*}{ Dimensão e indicadores } & \multirow{2}{*}{ Descrição do indicador } & \multicolumn{2}{|c|}{ Peso } \\
\hline & & Dimensão & Índice \\
\hline \multicolumn{4}{|l|}{ D1 - Mobilidade e acessibilidade } \\
\hline Condições de deslocamento (CD) & Percurso casa/parque (indicador subjetivo). & $1 / 2$ & $1 / 10$ \\
\hline Tempo de deslocamento (TD) & Proporção de pessoas que levam até $1 \mathrm{~h}$ para chegar ao parque. & $1 / 2$ & $1 / 10$ \\
\hline \multicolumn{4}{|l|}{ D2 - Condições ambientais urbanas } \\
\hline Arborização no entorno da residência (AE) & $\begin{array}{l}\text { Proporção de pessoas que moram em domicílios cujo entorno } \\
\text { possui arborização. }\end{array}$ & $1 / 8$ & $1 / 40$ \\
\hline Bem-estar e saúde (BS) & Aspecto subjetivo (indicador subjetivo). & $1 / 8$ & $1 / 40$ \\
\hline Clima e conforto (CC) & Aspecto subjetivo (indicador subjetivo). & $1 / 8$ & $1 / 40$ \\
\hline $\begin{array}{l}\text { Relação áreas verdes e qualidade de vida } \\
\text { (AQ) }\end{array}$ & Aspecto subjetivo (indicador subjetivo). & $1 / 8$ & $1 / 40$ \\
\hline $\begin{array}{l}\text { Qualidade de vida durante a permanência } \\
\text { no parque (QD) }\end{array}$ & Aspecto subjetivo (indicador subjetivo). & $1 / 8$ & $1 / 40$ \\
\hline $\begin{array}{l}\text { Qualidade de vida depois da permanência } \\
\text { no parque (QP) }\end{array}$ & Aspecto subjetivo (indicador subjetivo). & $1 / 8$ & $1 / 40$ \\
\hline Poluição no entorno da residência (PE) & $\begin{array}{l}\text { Proporção de pessoas que moram em domicílios cujo entorno } \\
\text { não possui poluição. }\end{array}$ & $1 / 8$ & $1 / 40$ \\
\hline Satisfação/Felicidade (SF) & Aspecto subjetivo (indicador subjetivo). & $1 / 8$ & $1 / 40$ \\
\hline \multicolumn{4}{|l|}{ D3 - Condições habitacionais urbanas } \\
\hline Calçada (CÇ) & $\begin{array}{l}\text { Proporção de pessoas que moram em domicílios cujo entorno } \\
\text { possui calçada. }\end{array}$ & $1 / 4$ & $1 / 20$ \\
\hline Densidade de banheiro (DB) & $\begin{array}{l}\text { Proporção de pessoas que moram em domicílios com até quatro } \\
\text { residentes por banheiro. }\end{array}$ & $1 / 4$ & $1 / 20$ \\
\hline Densidade domiciliar (DD) & $\begin{array}{l}\text { Proporção de pessoas que moram em domicílios com até quatro } \\
\text { residentes. }\end{array}$ & $1 / 4$ & $1 / 20$ \\
\hline Energia (EG) & $\begin{array}{l}\text { Proporção de pessoas que moram em domicílios com } \\
\text { atendimento de energia. }\end{array}$ & $1 / 4$ & $1 / 20$ \\
\hline \multicolumn{4}{|l|}{ D4 - Serviços coletivos urbanos } \\
\hline Atendimento de água (AG) & $\begin{array}{l}\text { Proporção de pessoas que moram em domicílios com } \\
\text { atendimento de água. }\end{array}$ & $1 / 3$ & $1 / 15$ \\
\hline Atendimento de esgoto (AE) & $\begin{array}{l}\text { Proporção de pessoas que moram em domicílios com } \\
\text { atendimento de esgoto. }\end{array}$ & $1 / 3$ & $1 / 15$ \\
\hline Coleta de resíduos (CR) & $\begin{array}{l}\text { Proporção de pessoas que moram em domicílios com coleta de } \\
\text { resíduos. }\end{array}$ & $1 / 3$ & $1 / 15$ \\
\hline \multicolumn{4}{|l|}{ D5 - Infraestrutura urbana } \\
\hline Iluminação pública (IP) & $\begin{array}{l}\text { Proporção de pessoas que moram em domicílios cujo entorno } \\
\text { possui iluminação pública. }\end{array}$ & $1 / 4$ & $1 / 20$ \\
\hline Logradouro (LG) & $\begin{array}{l}\text { Proporção de pessoas que moram em domicílios cujo entorno } \\
\text { possui logradouro. }\end{array}$ & $1 / 4$ & $1 / 20$ \\
\hline Pavimentação (PV) & $\begin{array}{l}\text { Proporção de pessoas que moram em domicílios cujo entorno } \\
\text { possui pavimentação. }\end{array}$ & $1 / 4$ & $1 / 20$ \\
\hline Rampa de acessibilidade (RP) & $\begin{array}{l}\text { Proporção de pessoas que moram em domicílios cujo entorno } \\
\text { possui rampa para cadeirante. }\end{array}$ & $1 / 4$ & $1 / 20$ \\
\hline
\end{tabular}

Fonte: adaptada de Ribeiro e Ribeiro (2013).

Figura 2 - Estrutura geral do Ibeav

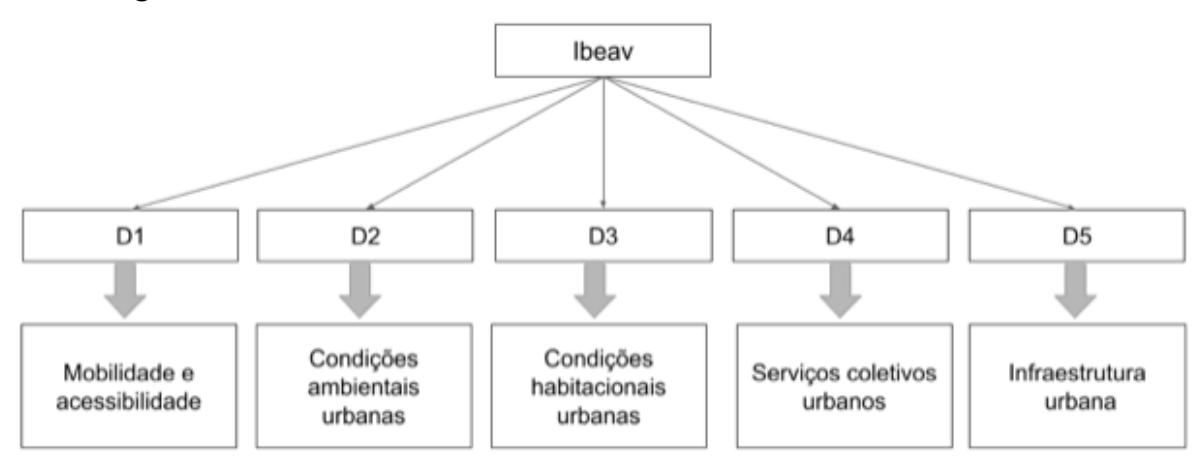

Fonte: adaptada de Ribeiro e Ribeiro (2013). 
O questionário foi baseado no trabalho de Donegan (2016), que investiga o espaço livre público a partir do uso, das atividades e do perfil dos frequentadores. Além disso, considerou prioritariamente todos os indicadores e as questões levantadas na metodologia da pesquisa.

Para definir o tamanho da amostra, como auxílio do sítio eletrônico de estatística ${ }^{4}$, foi considerada a população total de João Pessoa, estimada pelo IBGE (INSTITUTO..., 2019) em 800.323 pessoas para o ano de 2018. Com a definição do intervalo e do nível de confiança de 10 e 95\%, respectivamente, obteve-se um total de 192 questionários para os dois parques. E, visando otimizar a análise dos resultados, optou-se por aplicar 200 questionários, sendo $100 \mathrm{em}$ cada área de pesquisa. A pesquisa empregada buscou capturar variações, tanto em relação ao uso quanto às pessoas, assim, os questionários foram aplicados em horários variados. O questionário final, aprovado pelo Comitê de Ética do Centro de Ciências da Saúde (CCS) da UFPB (CAAE: 94826418.9.0000.5188) em 5 de setembro de 2018, foi aplicado nos meses de outubro, novembro e dezembro do mesmo ano nos dias úteis e nos finais de semana.

A tabulação, a análise e o tratamento dos dados foram realizados com o auxílio do Excel e, para a interpretação dos dados qualitativos, foi elaborada uma tabela em que, para cada resposta, foram atribuídos pesos de 0,2 a 1,0 (mínimo e máximo, respectivamente). Os indicadores subjetivos foram calculados a partir da Equação 1:

Ind $=\frac{\left(P_{1} * R_{1}\right)+\left(P_{2} * R_{2}\right)+\left(P_{3} * R_{3}\right)+\left(P_{4} * R_{4}\right)+\left(P_{5} * R_{5}\right)}{A}$

Em síntese, a Equação 1 também pode ser representada de acordo com a Equação 2:

Ind $=\frac{1}{A} \sum_{i=1}^{n}\left(P_{i} * R_{i}\right)$

Onde:

Ind $=$ indicador;

$P_{i}=$ peso de cada resposta (correspondente à satisfação);

$R_{i}=$ resposta obtida; e

$A=$ espaço amostral.

A Tabela 1 expõe, de maneira geral, a representação gráfica dos cálculos dos indicadores subjetivos.

O cálculo dos indicadores subjetivos utiliza os resultados das médias simples obtidas em cada indicador considerado, além dos seus pesos atribuídos de acordo com cada dimensão. Já o cálculo dos indicadores objetivos foi obtido a partir da Equação 3.

Ind $=\frac{N_{r p}}{N_{t}}$

Onde:

Ind $=$ indicador;

$N_{r p}=$ número de respostas positivas; e

$N_{t}=$ número total de pessoas entrevistadas.

Tabela 1 - Representação geral do cálculo dos indicadores subjetivos

\begin{tabular}{l|l|l|l}
\hline $\boldsymbol{I}$ & $\boldsymbol{P i}$ & $\boldsymbol{R i}$ & $\left(\boldsymbol{P} \boldsymbol{i}^{*} \boldsymbol{R i}\right)$ \\
\hline $\mathbf{1}$ & 0,2 & & \\
$\mathbf{2}$ & 0,4 & & \\
$\mathbf{3}$ & 0,6 & & \\
$\mathbf{4}$ & 0,8 & & \\
$\mathbf{5}$ & 1 & & \\
\hline
\end{tabular}

${ }^{4}$ Disponível em: https://www.surveysystem.com/sscalc.htm. 
Para a análise do Ibeav final, foi considerada a escala gráfica do Ibeu, em que, quanto mais próximo de 1, melhores as condições de qualidade de vida e de bem-estar urbano, assim como, quanto mais próximo de zero, piores são essas condições. Para a análise e a interpretação dos resultados, foram consideradas as siglas PSL para o Parque Solon de Lucena e Pzac para o Parque Zoobotânico Arruda Câmara.

\section{Áreas de pesquisa}

A cidade de João Pessoa, $\mathrm{PB}^{5}$, apresentada na Figura 3, é a terceira cidade mais antiga do Brasil, com uma população estimada pelo IBGE (INSTITUTO..., 2019) em 800.323 habitantes para o ano de 2018. Além disso, apresenta um total de 12 municípios em sua região metropolitana, que são: Bayeux, Cabedelo, João Pessoa, Santa Rita, Lucena, Cruz do Espírito Santo, Mamanguape, Rio Tinto, Alhandra, Pitimbu, Conde e Caaporã. O município de João Pessoa apresenta uma área que corresponde a $211,474 \mathrm{~km}^{2}$ com o espaço territorial entre as coordenadas $07^{\circ} 10^{\prime}$ 'S e e $34^{\circ} 50^{\prime} \mathrm{W}$, fazendo ligação com os estados de Pernambuco ao sul e Rio Grande do Norte ao norte (JOÃO PESSOA, 2012).

Figura 3 - Localização da cidade de João Pessoa, PB

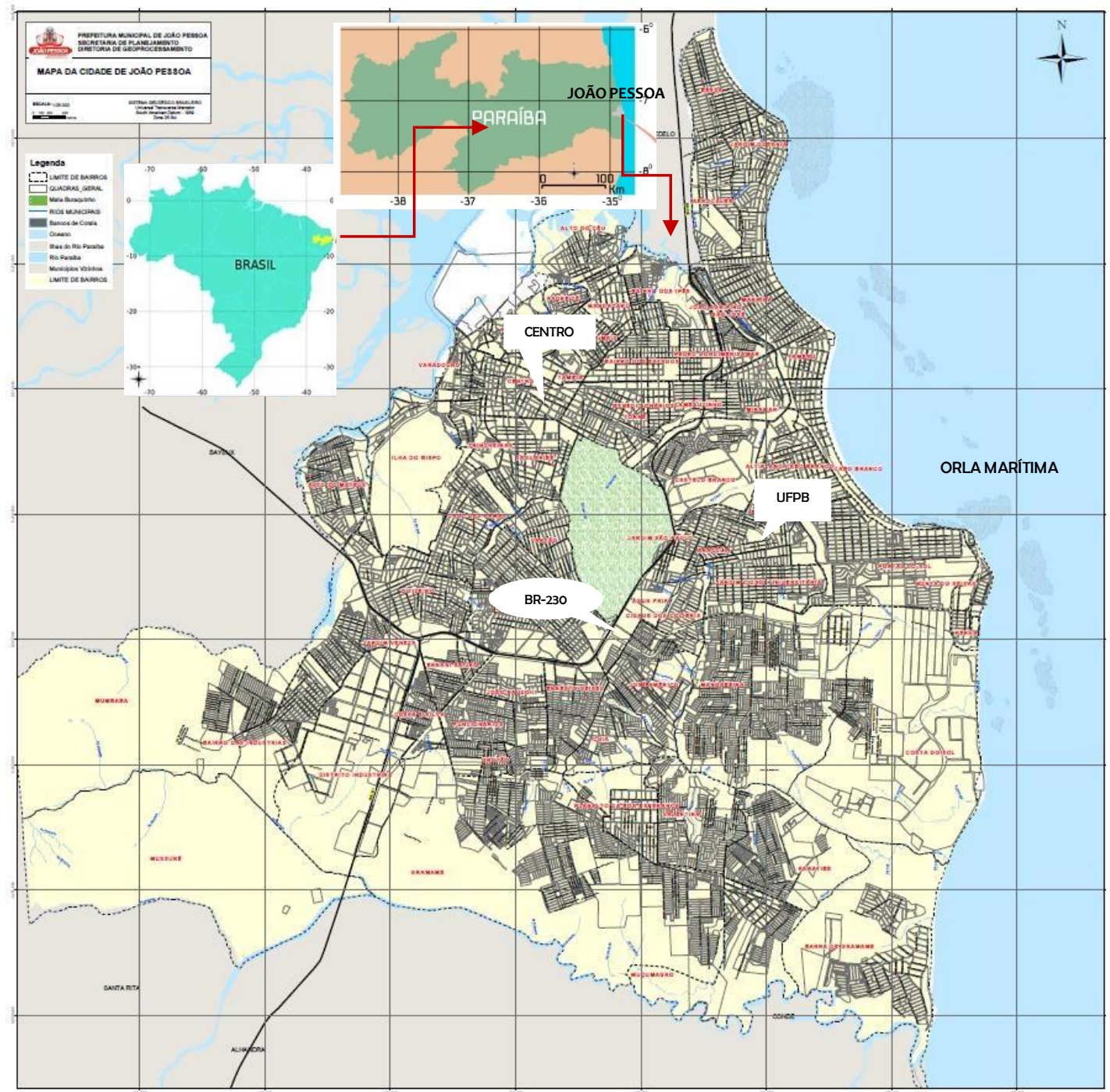

Fonte: adaptada de Prefeitura Municipal de João Pessoa (2020) com Google Maps (2019).

${ }^{5}$ Disponível em: http://geo.joaopessoa.pb.gov.br/digeoc/mapas/Mapa\%20de\%20Joao\%20Pessoa_90x90.pdf 
Entre as áreas verdes existentes no município, dois parques urbanos ganham destaque, principalmente por se tratar dos mais antigos da cidade, o Parque Zoobotânico Arruda Câmara e o Parque Solon de Lucena, destacados na Figura 4.

A escolha das áreas verdes considerou não apenas o fato de serem os parques mais antigos da cidade, mas, principalmente, por representarem espaços verdes livres consolidados na paisagem intraurbana da cidade e estarem diretamente ligados ao processo de urbanização e expansão da cidade. O PSL representa, além de um espaço de lazer, uma área de permanência e de circulação, principalmente por estar localizado na região central da cidade. Por outro lado, o Pzac, popularmente conhecido como "Bica", também apresenta uma localização privilegiada já que está dentro do perímetro urbano da cidade e, assim como o Parque Solon de Lucena, também fez parte do processo de urbanização e expansão urbana da cidade de João Pessoa. Além desses aspectos bastante relevantes também houve uma inquietação quanto à realização de um estudo comparativo entre esses dois espaços, visto que esse tipo de pesquisa ainda não é encontrado.

\section{Figura 4 - Áreas verdes e localização dos Parques Solon de Lucena e Zoobotânico Arruda Câmara em João Pessoa, PB}

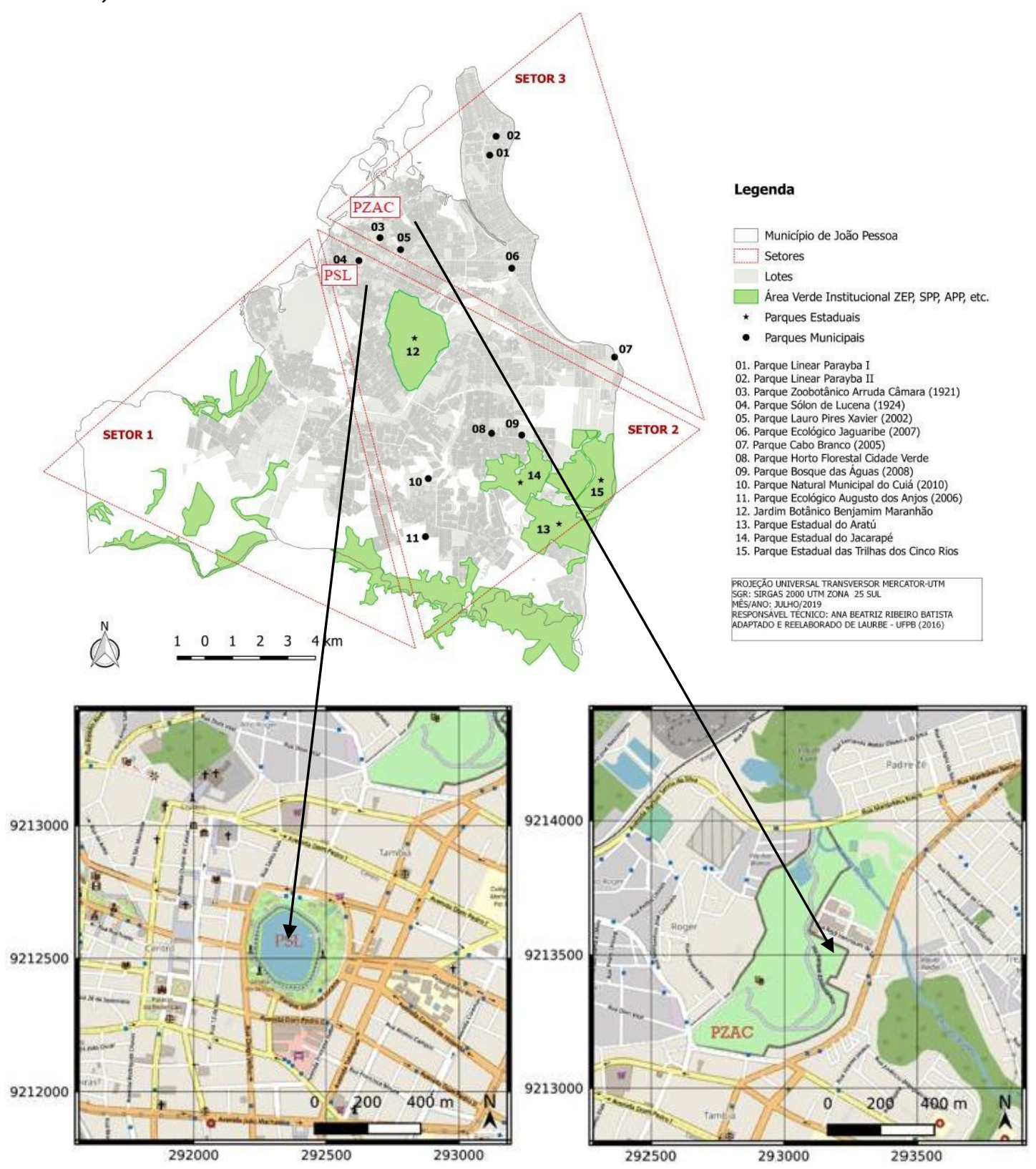

Fonte: adaptada de Batista (2019), com dados do IBGE (INSTITUTO..., 2019) e do Open Street Maps (OPEN..., 2019) (Datum geográfico SIRGAS 2000, Zona UTM 25). 


\section{O Parque Solon de Lucena e o Parque Zoobotânico Arruda Câmara}

Antiga Lagoa dos Irerês, o Parque Solon de Lucena ou "Parque da Lagoa" representa um dos principais pontos de expansão urbana da cidade. Foi inaugurado oficialmente em 1939 e tombado pelo Instituto do Patrimônio Histórico e Artístico do Estado da Paraíba (Iphaep) em agosto de 1980 (JOÃO..., 2012). Em 2014, a Prefeitura de João Pessoa iniciou o projeto de revitalização do "Parque da Lagoa", que foi denominado de "Revitalização e Modernização do Parque Solon de Lucena".

Já o Parque Zoobotânico Arruda Câmara foi criado no ano de 1921, mas inaugurado apenas no ano seguinte. É o parque mais antigo da cidade e teve seu nome definido para homenagear o frade Manuel Arruda Câmara. Com uma área de aproximadamente 26,8 ha, o espaço também é conhecido como "Parque da Bica", referência que se faz em relação às nascentes ali presentes. No ano de 1999, foi registrado no Instituto Brasileiro do Meio Ambiente e dos Recursos Naturais Renováveis (Ibama) como Parque Zoobotânico Arruda Câmara (JOÃO..., 2012). As Figuras 5a e 5b mostram o Parque Solon de Lucena e as Figuras 6a e 6b, o Parque Zoobotânico Arruda Câmara.

\section{Resultados e discussão}

Os resultados a que se chegou na pesquisa, assim como as discussões sobre cada dimensão e indicadores avaliados são apresentados comparativamente entre os dois parques analisados.

A princípio foi realizada a caracterização dos usuários e, para isso, foram apresentados questionamentos sobre gênero, faixa etária, tempo de permanência no parque e principal motivação para utilizar o espaço. Os dados apontaram que, em relação ao gênero, tanto no PSL como no Pzac a maior parte dos usuários é do gênero feminino, $62 \%$ e $67 \%$, respectivamente. Em relação à faixa etária, no PSL 51\% encontravam-se dos 18 aos 30 anos, 20\% dos 31 aos 40 anos, 19\% dos 41 aos 50 anos, 7\% dos 51 aos 60 anos e 3\% maiores de 60 anos, enquanto no Pzac 58\% estavam dos 18 aos 30 anos, 29\% dos 31 aos 40, 8\% dos 41 aos 50 anos, 3\% dos 51 aos 60 anos e apenas $2 \%$ maiores de 60 anos.

\section{Figura 5 - Parque Solon de Lucena}

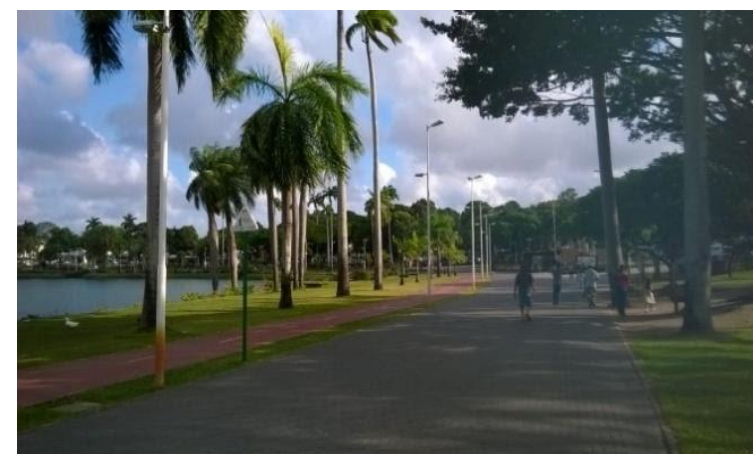

(a)

Figura 6 - Parque Zoobotânico Arruda Câmara

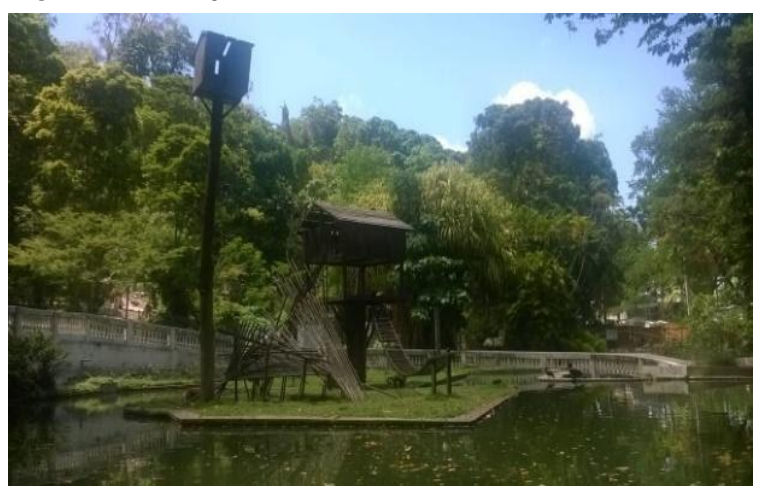

(a)

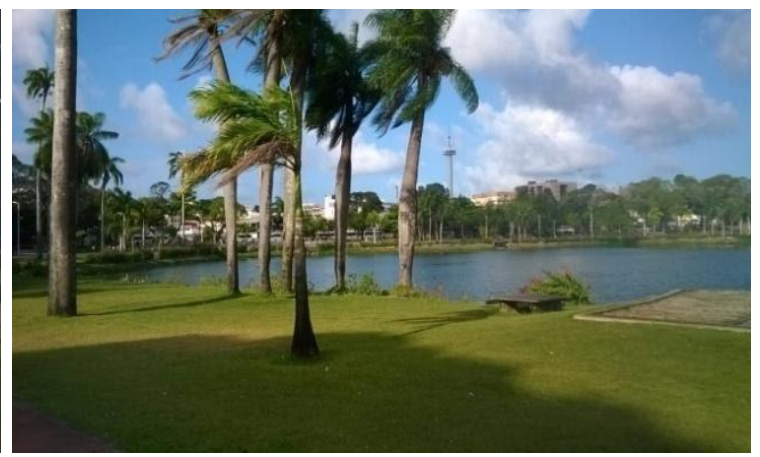

(b)

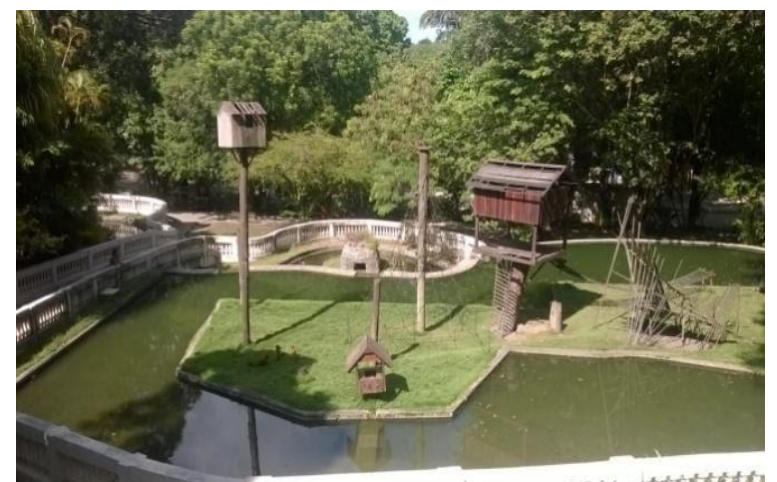

(b) 
Sobre as principais motivações que faziam com que os entrevistados utilizassem os parques, tanto no PSL quanto no Pzac, estão o lazer e o passeio com crianças. O fato reforça a hipótese apresentada de que os espaços verdes proporcionam tais aspectos que se relacionam à qualidade de vida e ao bem-estar.

Quanto ao tempo de permanência dos usuários nos dois parques, a maioria dos entrevistados afirmou que fica no espaço entre 1 h e 1 h $30 \mathrm{~min}$. Tal característica reforça a ideia de que esses parques urbanos, além de áreas livres e verdes, também são espaços de permanência dentro da cidade destinados principalmente ao lazer.

$\mathrm{Na}$ análise da dimensão D1 mobilidade e acessibilidade, que considerou o indicador objetivo tempo de deslocamento (TD) e o indicador subjetivo condições de deslocamento (CD), o parque com melhor resultado foi o PSL. Tal resultado pode ter sido influenciado pela localização e pela maior disponibilidade de transporte coletivo urbano naquela área da cidade, visto que $64 \%$ dos usuários do PSL utilizam o transporte coletivo para ir ao parque e apenas $25 \%$ utilizam esse sistema de transporte para ir ao Pzac. Por outro lado, $71 \%$ dos frequentadores do Pzac utilizam o transporte individual, enquanto somente $27 \%$ utilizam esse sistema de transporte para acessar o PSL. Em relação a este resultado, pontuam-se a falta de áreas destinadas ao estacionamento no PSL e a maior disponibilidade de transporte público coletivo. Também vale destacar que o Pzac encontra-se localizado em uma área da cidade com o menor nível de acessibilidade por transporte público quando comparado com o PSL. Outro aspecto também relevante no Pzac é a restrição em relação aos dias e aos horários das atividades destinadas ao público. Os resultados são observados na Figura 7.

A partir dos resultados obtidos na dimensão D1, foram calculados os resultados dos indicadores condições de deslocamento (CD) e tempo de deslocamento (TD) para os usuários dos parques.

Além disso, os frequentadores foram indagados sobre o tipo de transporte mais utilizado para chegarem aos parques. No PSL, 64\% afirmaram que utilizam o transporte coletivo como principal meio de deslocamento, $27 \%$ o transporte motorizado individual e $9 \%$ o transporte não motorizado. No Pzac, $71 \%$ utilizam transporte motorizado individual, visto que já foi mencionado que esse espaço está localizado em uma área com baixa disponibilidade de transporte coletivo urbano, enquanto $25 \%$ utilizam o transporte coletivo e $4 \%$ o transporte não motorizado. A partir dos resultados, foram calculados os valores para cada indicador da dimensão D1 conforme apresentado na Tabela 2.

Figura 7 - Indicadores da D1 (mobilidade e acessibilidade)

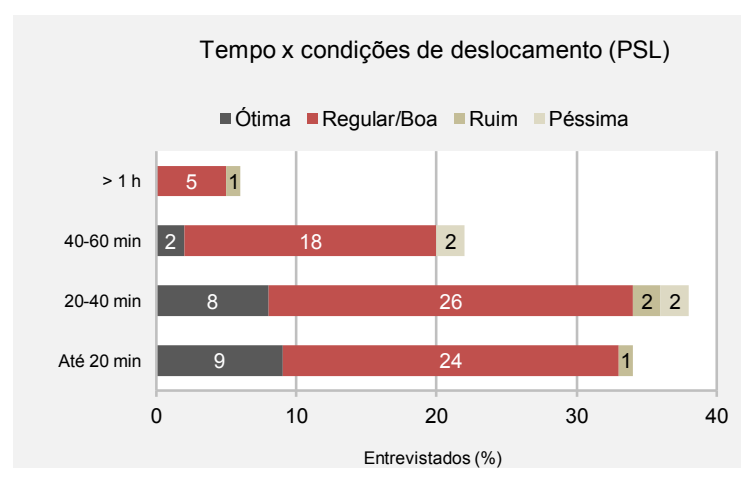

(a)

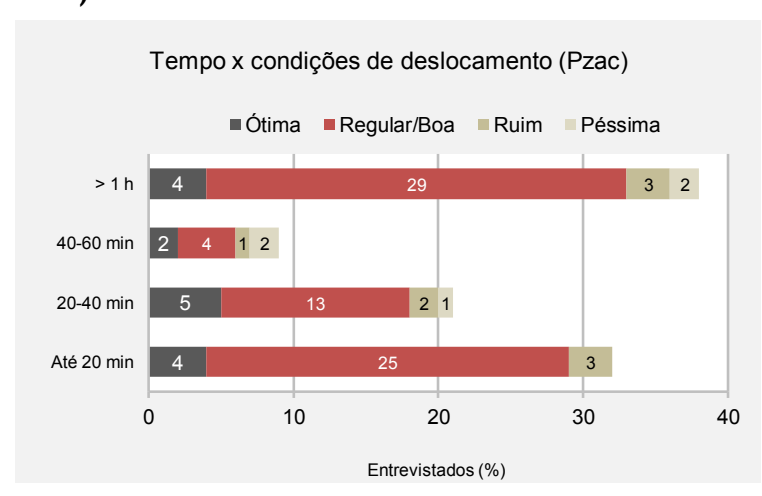

(b)

Tabela 2 - Resultado dos indicadores de D1 (mobilidade e acessibilidade) nos dois parques

\begin{tabular}{c|c}
\hline \multicolumn{2}{c}{ D1 $=\boldsymbol{T D}+\boldsymbol{C D}$} \\
\hline Parque Solon de Lucena (PSL) & 0,155 \\
Parque Zoobotânico Arruda Câmara (Pzac) & 0,121 \\
\hline
\end{tabular}


Na dimensão D2 condições ambientais urbanas, que engloba indicadores subjetivos e objetivos, todos esses apresentaram valores expressivos, principalmente em relação ao indicador poluição no entorno da residência (PE), um aspecto relevante, visto que a hipótese principal da pesquisa se encontra apoiada precipuamente na utilização de indicadores subjetivos para avaliar a qualidade de vida e o bem-estar das pessoas. Nesse sentido, percebe-se que os maiores valores se referem aos indicadores subjetivos em relação à sensação de melhor qualidade de vida durante e depois da utilização do espaço. Os usuários também relataram sentimentos de satisfação, felicidade, saúde e bem-estar no parque, ou seja, ao frequentarem aquele espaço, esses sentimentos foram melhorados. Nesse quesito o PSL apresentou os maiores percentuais. Em números mais específicos, para o PSL, os resultados dos indicadores qualidade de vida durante a permanência no parque (QD), relação áreas verdes e qualidade de vida (AQ), qualidade de vida depois da permanência no parque (QP), satisfação/felicidade (SF), clima e conforto (CC) e bem-estar e saúde (BS) foram 0,92, 0,912, 0,91, 0,91, 0,886 e 0,868, respectivamente. Para o Pzac, os valores foram 0,896, 0,886, 0,876, 0,85, 0,828 e 0,788 , respectivamente. De modo geral, esses valores indicam que, quanto mais próximo de 1 , melhor o seu resultado. Os resultados obtidos estão ilustrados nas Figuras $8 \mathrm{a}$ e $8 \mathrm{~b}$.

Vale destacar que nessa dimensão, que considera indicadores subjetivos, o método utilizado tentou buscar maior aproximação em relação à realidade de cada usuário entrevistado. Entretanto, a captura de dados subjetivos também pode ser entendida como uma atividade que apresenta limitação no que se refere ao seu dimensionamento.

Em relação aos indicadores objetivos, o Pzac apresentou valor de 0,5 e o PSL de 0,55 para poluição no entorno da residência (PE). Em relação ao indicador arborização no entorno da residência (AE), o Pzac apresentou melhor resultado igual a 0,73, enquanto o PSL obteve 0,65. Entretanto, esses indicadores consideram apenas o entorno do domicílio. Esses resultados podem ser observados nas Figuras 9a e 9b.

A partir dos dados referentes aos indicadores subjetivos da dimensão D2 condições ambientais urbanas, os seguintes resultados foram obtidos conforme a Tabela 3 .

Figura 8 - Indicadores da D2 (condições ambientais urbanas) no PSL e no Pzac

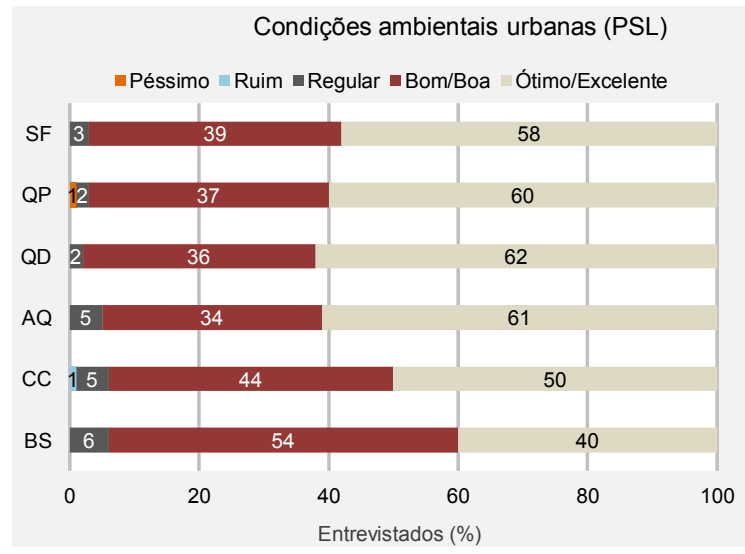

(a)

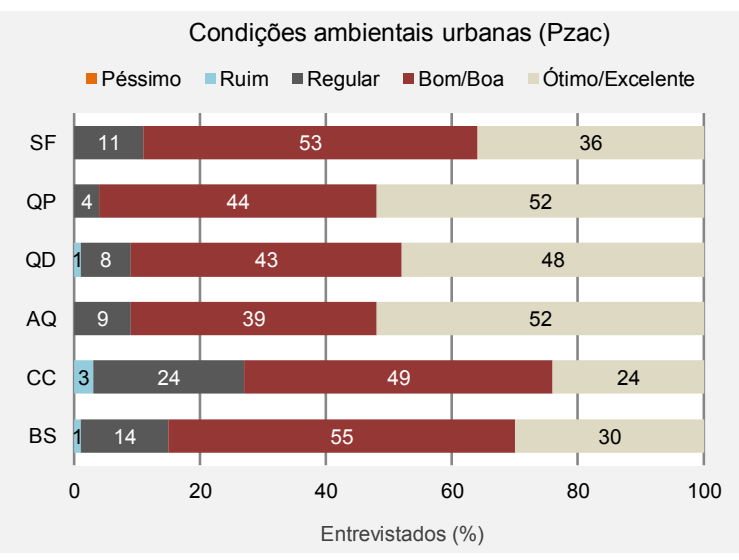

(b)

Figura 9 - Indicadores da D2 (condições ambientais urbanas) nos dois casos

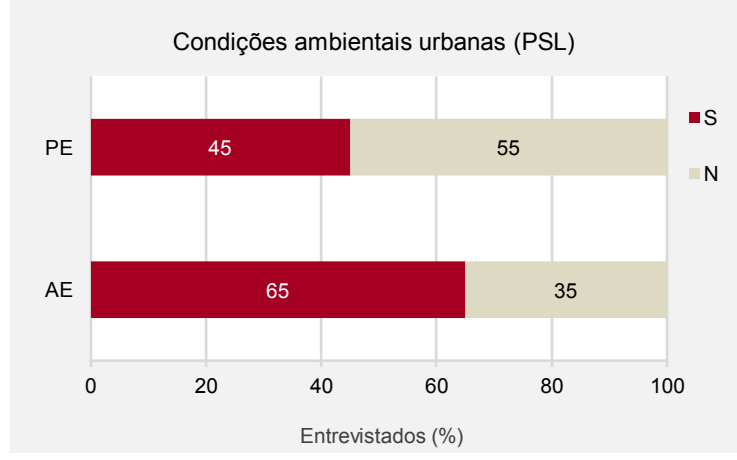

(a)

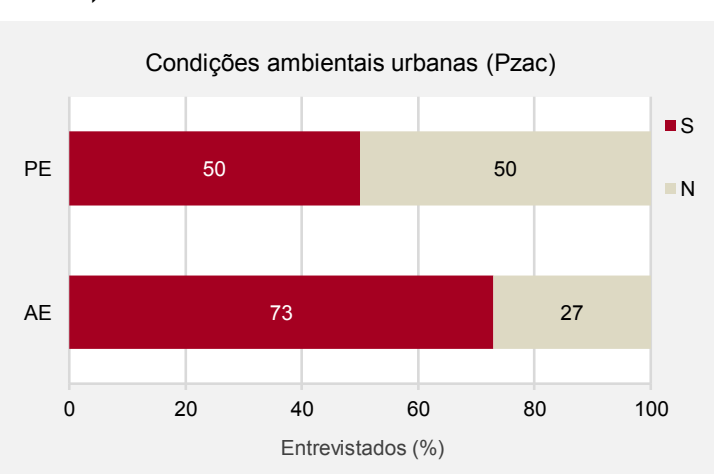

(b) 
Tabela 3 - Resultado dos indicadores de D2 (condições ambientais urbanas) nos dois parques

\begin{tabular}{c|c}
\hline \multicolumn{2}{c}{$\mathbf{D} 2 \boldsymbol{S F}+\boldsymbol{Q P}+\boldsymbol{Q D}+\boldsymbol{A Q}+\boldsymbol{C C}+\boldsymbol{B S}+\boldsymbol{P E}+\boldsymbol{A E}$} \\
\hline Parque Solon de Lucena (PSL) & 0,165 \\
Parque Zoobotânico Arruda Câmara (Pzac) & 0,159 \\
\hline
\end{tabular}

Sobre D3 condições habitacionais urbanas, essa dimensão utiliza indicadores presentes na composição do Ibeu e constitui o âmbito dos aspectos básicos para boas condições de vida, como a existência de banheiro e o fornecimento de energia elétrica. Nesse caso, os resultados dos dois parques estiveram próximos. Entretanto, os indicadores mais expressivos foram densidade de banheiro (DB) e energia (EG) para o PSL, com valores de 0,97 e 0,96, e para o Pzac, de 0,92 e 0,94. Quanto aos demais indicadores da dimensão, calçada (CÇ) e densidade domiciliar (DD), o Pzac apresentou os maiores valores, de 0,92 e 0,8, e o PSL os menores, de 0,85 e 0,78. De modo geral, os indicadores que compõem a dimensão D3 apontaram que os usuários dos dois parques apresentam boas condições habitacionais urbanas, como observado nas Figuras 10a e 10b. Tais resultados reforçam a importância desses elementos enquanto indicadores de qualidade de vida e bem-estar.

A partir dos resultados, foram calculados os valores para cada indicador da dimensão D3 conforme a Tabela 4.

Sobre D4 serviços coletivos urbanos, o Pzac apresentou os melhores resultados em relação ao PSL, sendo os indicadores com maior pontuação os de atendimento de água (AG) e de coleta de resíduos (CR): o PSL com 0,96 e 0,92 e o Pzac com 0,95 e 0,9. Esses indicadores também são considerados na composição do Ibeu e, de modo geral, indicam que os usuários dos dois parques dispõem, quase que totalmente, de tais serviços. Tais resultados encontram-se ilustrados nas Figuras 11a e $11 \mathrm{~b}$.

A partir dos resultados da pesquisa, foram obtidos os dados dos indicadores da D4 (serviços coletivos urbanos). Vale pontuar que, para o cálculo dos indicadores, apresentados na Tabela 5, foram mantidas apenas as respostas afirmativas.

Os indicadores D5 infraestrutura urbana procuraram englobar os aspectos que influenciam a qualidade do espaço refletindo na qualidade de vida das pessoas.

Vale destacar que esses indicadores referem-se ao espaço residencial dos entrevistados, e não ao parque frequentado. Entretanto, é legítimo ressaltar que tais condições estão diretamente relacionadas à qualidade de vida e ao bem-estar das pessoas.

Em termos mais específicos, o menor valor observado em relação aos indicadores se refere ao indicador rampa (RP), que apresentou valores de 0,25 e 0,23 para o PSL e o Pzac, respectivamente. Entretanto, os indicadores iluminação pública (IP), logradouro (LG) e pavimentação (PV) apresentaram, respectivamente, valores de 1, 0,8 e 0,65 para o PSL e de 0,94, 0,82 e 0,82 para o Pzac. Vale destacar que os dados refletem as condições de infraestrutura urbana que os frequentadores dos parques enfrentam.

Em relação à percepção do usuário sobre a acessibilidade, de maneira geral, o PSL foi o mais bem avaliado. Entretanto, vale salientar que o Parque encontra-se localizado em uma região central da cidade e representa um ponto de referência para inúmeras atividades das pessoas, além de apresentar maior disponibilidade de transporte público. Os resultados estão ilustrados nas Figuras 12a e 12b.

A partir dos dados capturados, posteriormente, foram obtidos os valores dos indicadores da dimensão, sendo consideradas apenas as respostas afirmativas para a realização dos respectivos cálculos (Tabela 6).

Assim, a partir dos resultados de todos os indicadores e, posteriormente, das cinco dimensões do índice, foi calculado o Ibeav final para o PSL e o Pzac apresentados na Tabela 7.

Em síntese, os resultados obtidos a partir das cinco dimensões abordadas, aplicadas no PSL e no Pzac, são apresentados na Figura 13. Desse modo, é possível observar, comparativamente, o modo como se comporta cada dimensão em cada parque separadamente.

A análise comparativa do resultado final do Ibeav, tanto para o PSL quanto para o Pzac, identificou o índice de qualidade de vida e de bem-estar a partir da escala comparativa do Ibeu, conforme apresenta a Figura 14.

Partindo dessa perspectiva, pontua-se que o PSL representa uma área com boas condições de qualidade de vida e de bem-estar, de acordo com seus usuários. Entretanto, vale enfatizar que, recentemente, o Parque passou por um processo de revitalização, o que pode ter influenciado o resultado final obtido, enquanto o Pzac aponta condições médias de qualidade de vida e de bem-estar urbano para seus usuários. 
Figura 10 - Indicadores da D3 (condições habitacionais urbanas) nos dois casos

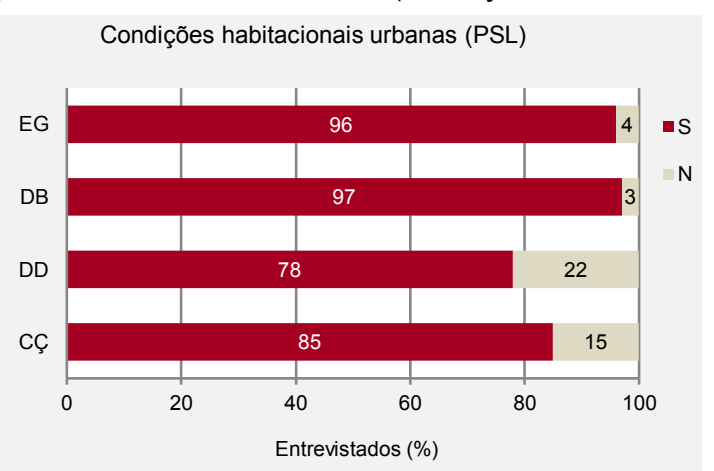

(a)

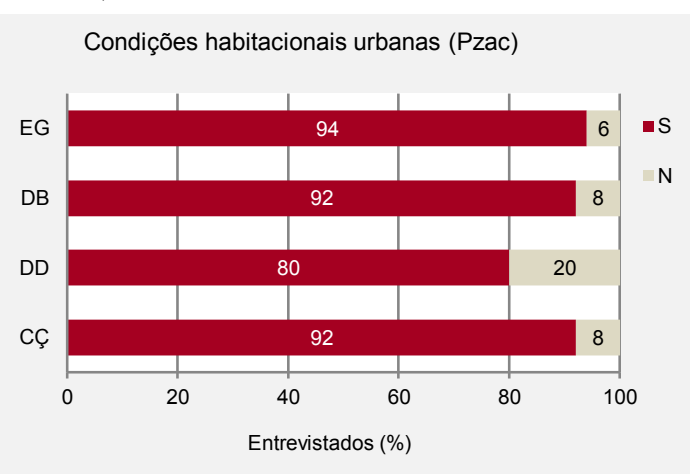

(b)

Tabela 4 - Resultados dos indicadores de D3 (condições habitacionais urbanas) nos dois parques

\begin{tabular}{c|c}
\hline \multicolumn{3}{c}{ D3 = EG+ $\boldsymbol{D B}+\boldsymbol{D D}+\boldsymbol{C C}$} \\
\hline Parque Solon de Lucena (PSL) & 0,178 \\
Parque Zoobotânico Arruda Câmara (Pzac) & 0,179 \\
\hline
\end{tabular}

Figura 11 - Indicadores da D4 (serviços coletivos urbanos) nos dois casos

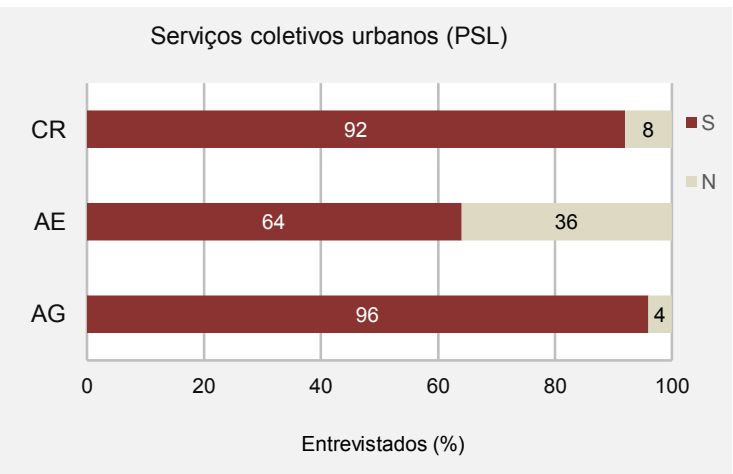

(a)

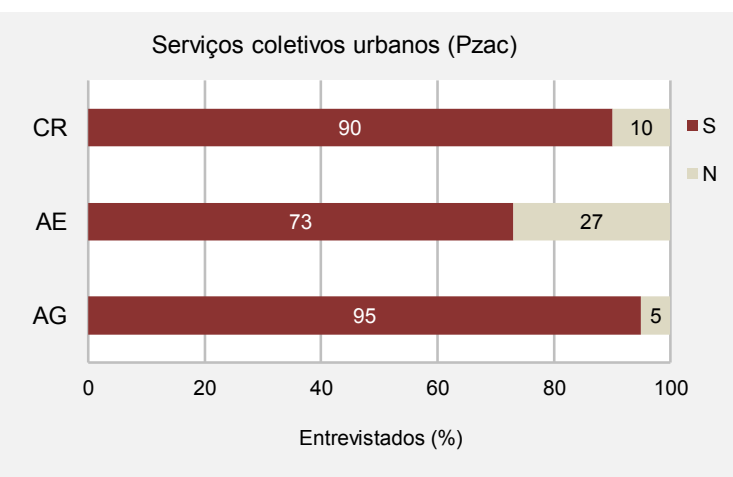

(b)

Tabela 5 - Resultados dos indicadores de D4 (serviçoes coletivos urbanos) nos dois parques

\begin{tabular}{c|c}
\hline \multicolumn{2}{c}{ D4 = $\boldsymbol{C R}+\boldsymbol{A E}+\boldsymbol{A G}$} \\
\hline Parque Solon de Lucena (PSL) & 0,168 \\
Parque Zoobotânico Arruda Câmara (Pzac) & 0,172 \\
\hline
\end{tabular}

Figura 12 - Indicadores da D5 (infraestrutura urbana) nos dois casos

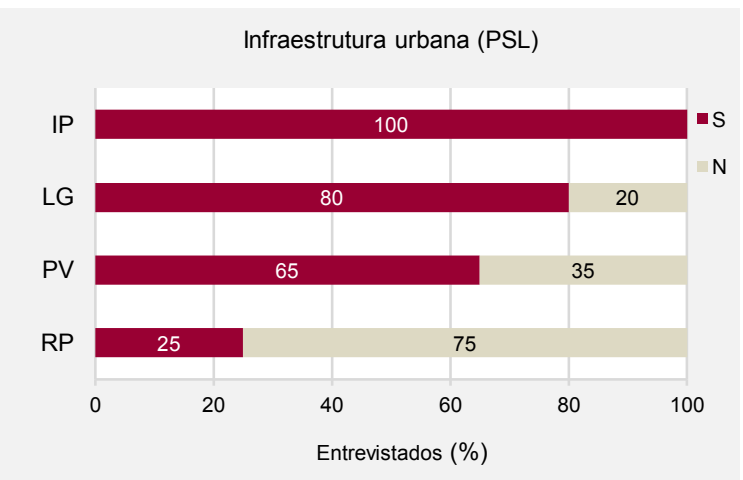

(a)

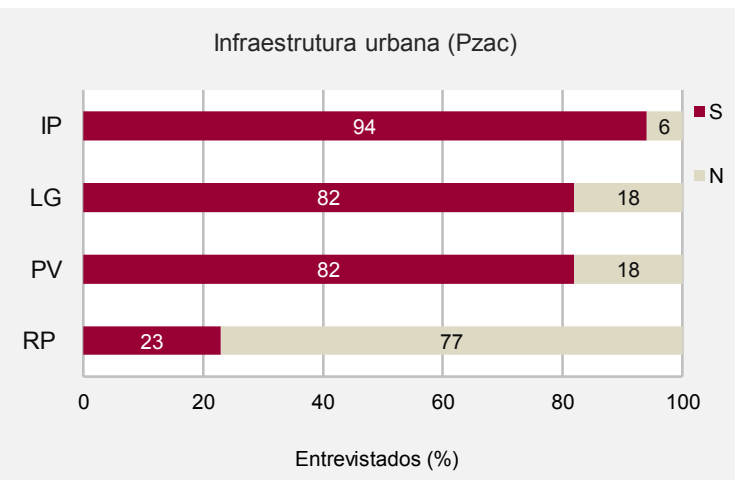

(b) 
Tabela 6 - Resultados dos indicadores de D5 (infraestrutura urbana) nos dois parques

\begin{tabular}{c|c}
\hline \multicolumn{3}{c}{ D5 = $\boldsymbol{I P}+\boldsymbol{L G}+\boldsymbol{P V}+\boldsymbol{R P}$} \\
\hline Parque Solon de Lucena (PSL) & 0,135 \\
Parque Zoobotânico Arruda Câmara (Pzac) & 0,140 \\
\hline
\end{tabular}

Tabela 7 - Resultados do Ibeav final (D1, D2, D3, D4 e D5) nos dois parques

\begin{tabular}{c|c}
\hline \multicolumn{3}{c}{ Ibeav $=\mathbf{D 1}+\boldsymbol{D 2}+\boldsymbol{D 3}+\boldsymbol{D 4}+\boldsymbol{D 5}$} \\
\hline Parque Solon de Lucena (PSL) & 0,802 \\
Parque Zoobotânico Arruda Câmara (Pzac) & 0,772 \\
\hline
\end{tabular}

Figura 13 - Síntese das dimensões analisadas

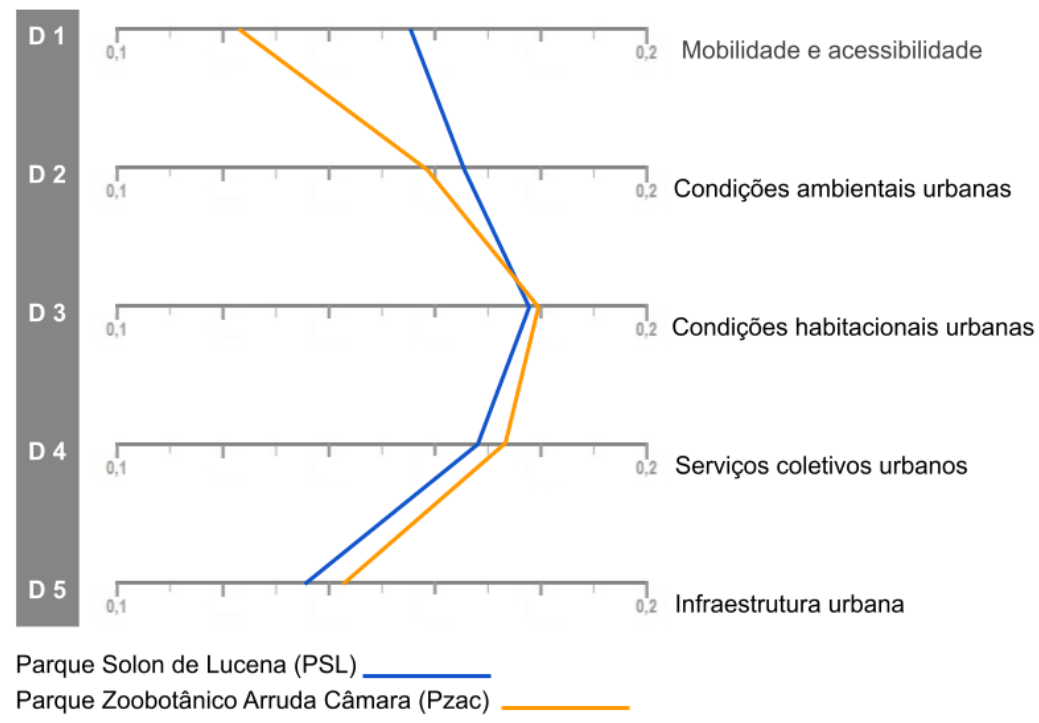

Figura 14 - Ibeav final dos usuários do PSL e do Pzac

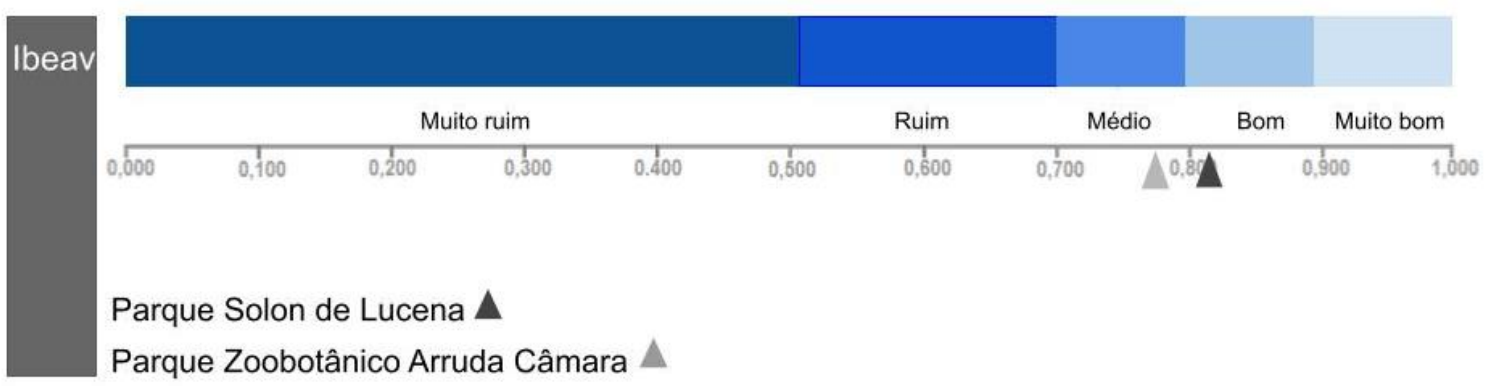

Fonte: elaborado a partir de Ribeiro e Ribeiro (2013).

\section{Conclusão}

O estudo buscou ampliar as discussões sobre a temática da qualidade de vida e do bem-estar das pessoas e, para isso, deu ênfase aos indicadores subjetivos a fim de que se pudesse realizar tal análise. Desse modo, considerando os recortes espaciais, foi possível constatar que os dois parques analisados representam duas áreas verdes bastante relevantes e influenciam a qualidade de vida e o bem-estar dos seus usuários.

Sendo assim, a partir da análise e do resultado final dos indicadores das cinco dimensões, observa-se que o PSL apresentou um Ibeav melhor quando comparado com o resultado do índice final do Pzac. Tais resultados apontam para algumas dimensões que se destacaram quando comparadas com outras. Entretanto, quando observadas separadamente, o Pzac apresentou melhores resultados nas dimensões D3, D4 e D5, que se referem às condições habitacionais urbanas, aos serviços coletivos urbanos e à infraestrutura urbana, 
respectivamente. Entretanto, ainda assim, o resultado final do PSL foi maior, o que apontou para uma área verde que, naquele momento, foi capaz de proporcionar mais qualidade de vida e bem-estar aos seus frequentadores.

Os aspectos que mais se destacam na pesquisa se referem principalmente à associação feita pelos usuários dos dois parques entre qualidade de vida e bem-estar, condições habitacionais urbanas e serviços coletivos urbanos os quais têm acesso. Nesse sentido, é pertinente afirmar que, considerando os indicadores utilizados, alguns aspectos sociais, como os indicadores das dimensões apontadas anteriormente, são fundamentais para que se possam elevar a qualidade de vida e o bem-estar das pessoas. Entretanto, ainda de acordo com os usuários pesquisados, esses elementos devem estar associados a aspectos subjetivos, como satisfação e felicidade, por exemplo.

Os resultados obtidos também reforçam as hipóteses do trabalho, ressaltando, com isso, a importância da presença de áreas verdes no espaço urbano e evidenciam que os usuários do PSL apresentam melhor qualidade de vida e bem-estar quando comparados com os do Pzac.

Outro ponto relevante da pesquisa se refere à metodologia utilizada, que, além de ter sido adaptada a partir de um método já consolidado, considerou indicadores subjetivos na sua composição, reforçando o que muitos estudos indicam sobre a relação áreas verdes e qualidade de vida e o bem urbano. Salienta-se, portanto, a importância dos aspectos subjetivos e do fato de serem considerados indicadores para compor os métodos que avaliam qualidade de vida e bem-estar. Vale enfatizar que, nesta pesquisa, tais indicadores foram determinantes para os resultados obtidos. Ressalta-se, ainda, que o índice final do Ibeav para os dois parques apresentou um resultado condizente com o determinado pelo Ibeu para o município de João Pessoa. Entretanto, toda ferramenta de pesquisa pode apresentar limitações, principalmente quando a temática é complexa e abrangente, assim como as especificidades que cada espaço apresenta.

A contribuição da pesquisa, seja pelo seu desenvolvimento, adaptação e aplicação do método Ibeav, ocorre, principalmente, pela proposição da utilização de indicadores subjetivos e objetivos. Sob essa ótica, foi possível identificar as cinco dimensões e os indicadores que contribuem para ampliar e/ou reduzir o índice de qualidade de vida de cada espaço avaliado. Tal aspecto pode ser entendido como uma forma de considerar que a qualidade de vida e o bem-estar das pessoas também estão relacionados a elementos imateriais e, para isso, deve-se considerar a reformulação ou o desenvolvimento de novos métodos de avaliação de qualidade de vida e bem-estar a partir de dimensões mais complexas. No caso específico do Ibeav, propõe-se replicar o método em outros espaços a fim de que se possam desenvolver outros estudos comparativos. É importante destacar que o campo das discussões sobre qualidade de vida e bem-estar deve envolver, além de questões sociais e econômicas, questões subjetivas, além de ferramentas que contemplem tais questões.

\section{Referências}

BANCO MUNDIAL. [Indicator]. Disponível em: https://data.worldbank.org/indicator/SI.POV.GINI. Acesso em: 19 out. 2020.

BATISTA, A. B. Espaços livres. João Pessoa, 2019. Trabalho de Conclusão de Curso (Graduação em Arquitetura e Urbanismo) - Curso de Arquitetura e Urbanismo, Universidade Federal da Paraíba, João Pessoa, 2019.

CHEN, Z.; XUA, B.; GAO, B. Assessing visual green effects of individual urban trees using airborne Lidar. Science of the Total Environment, v. 536, p. 232-244, 2015.

CONGER, B. W. On livability, liveability and the limited utility of quality of life rankings. The School of Public Policy, v. 7, p. 1-8, 2015.

DONEGAN, L. Qual é a sua praia? Arquitetura e sociedade em praias de Natal-RN. Natal, 2016. Tese (Doutorado em Arquitetura e Urbanismo) - Programa de Pós-Graduação em Arquitetura e Urbanismo, Universidade Federal do Rio Grande do Norte, Natal, 2016.

FARQUHAR, M. Definitions of quality of life: a taxonomy. Journal of Advanced Nursing, v. 20, n. 2, p. 502-508, 1995.

FIGUEIREDO, A. S. (org.). Índice de qualidade de vida urbana de Campo Grande-MS. Campo Grande: PLANURB, 2008. 
GOOGLE MAPS. [Imagens]. Disponível em:

https://www.google.com.br/maps/place/Jo\%C3\%A3o+Pessoa,+PB/@-7.1464332,--

$34.9516387,12 \mathrm{z} / \mathrm{data}=! 3 \mathrm{~m} 1 ! 4 \mathrm{~b} 1 ! 4 \mathrm{~m} 5 ! 3 \mathrm{~m} 4$ ! 1s0x7ace839019aa3d7:0x6e414a9c6d26db34!8m2!3d-

7.1194958!4d-34.8450118. Acesso em: 18 ago. 2019.

HERCULANO, S. C. A qualidade de vida e seus indicadores. In: HERCULANO, S. et al. (org.). Qualidade de vida e riscos ambientais. Niterói: Eduff, 2000.

INSTITUTO BRASILEIRO DE GEOGRAFIA E eSTATÍstICA. João Pessoa. Disponível em: https://www.ibge.gov.br/cidades-e-estados/pb/joao-pessoa.html. Acesso em: 30 out. 2019.

JOÃO PESSOA. Secretaria Municipal de Meio Ambiente. Plano Municipal de Conservação e

Recuperação da Mata Atlântica. João Pessoa: Secretaria Municipal de Meio Ambiente, 2012.

KAKLAUSKAS, A. et al. Quality of city life multiple criteria analysis. Cities, v. 72, p. 82-93, 2018.

LIRA, A. H. C. de et al. Avaliação da qualidade de vida urbana nos condomínios horizontais da cidade de João Pessoa, PB. Ambiente Construído, Porto Alegre, v. 17, n. 4, p. 285-304, out./dez. 2017.

MERCER HUMAN RESOURCE CONSULTING, MARSH \& MCLENNAN. Classificações de qualidade de vida de 2018. Disponível em: https://www.imercer.com/content/mobility/quality-of-living-cityrankings.html. Acesso em: 14 out. 2018.

NAHAS, M. I. P. et al. Metodologia de construção do índice de qualidade de vida urbana dos municípios brasileiros (IQVU-BR). In: ENCONTRO NACIONAL DE ESTUDOS POPULACIONAIS DA ASSOCIAÇÃO BRASILEIRA DE ESTUDOS POPULACIONAIS, 15., Caxambu, 2006. Anais [...] Caxambu, 2006.

NUMBEO. Data base of quality of life informations. Disponível em: https://www.numbeo.com/quality-oflife/region_rankings.jsp?Title=2012-Q1\%C2\%aeion=150. Acesso em: 14 out. 2018.

OPEN STREET. [Maps]. Disponível em: https://www.openstreetmap.org/\#map=4/-15.13/-53.19. Acesso em: 14 nov. 2019.

PREFEITURA MUNICIPAL DE JOÃO PESSOA. Diretoria de Geoprocessamento e Cadastro.

Disponível em: http://geo.joaopessoa.pb.gov.br/digeoc/htmls/2008.html. Acesso em: 08 nov. 2020.

PROGRAMA DAS NAÇÕES UNIDAS PARA O DESENVOLVIMENTO. Relatório do desenvolvimento Humano 2014: Sustentar o Progresso Humano: Reduzir as Vulnerabilidades e Reforçar a Resiliência. 2014. Disponível em: http://hdr.undp.org/sites/default/files/hdr14_summary_pt.pdf. Acesso em: 19 out. 2020.

RIBEIRO, L. C. de Q.; RIBEIRO, M. G. (org.). Ibeu: índice de bem-estar urbano. Rio de Janeiro: Letra Capital, Observatório das Metrópoles - IPPUR/UFRJ, 2013.

SEIDL, E. M. F.; ZANNON, C. M. L. da C. Qualidade de vida e saúde: aspectos conceituais e metodológicos. Cadernos de Saúde Pública, v. 20, n. 2, p. 580-588, mar./abr. 2004.

SILVA, J. F. D. Contributo dos espaços verdes para o bem-estar das populações: estudo de caso em Vila Real. Coimbra, 2014. Dissertação (Mestrado em Geografia Humana: Ordenamento do Território e Desenvolvimento) - Departamento de Geografia, Faculdade de Letras, Universidade de Coimbra, Coimbra, 2014.

SZEREMETA, B.; ZANNIN, P. H. T. A importância dos parques urbanos e áreas verdes na promoção da qualidade de vida em cidades. Revista Ra'e Ga, v. 29, p. 177-193, dez. 2013.

\section{Agradecimentos}

À Coordenação de Aperfeiçoamento de Pessoal de Nível Superior (Capes), pelo auxílio financeiro por meio de bolsa de estudo durante a pesquisa. 


\section{Juliana Cláudia Bezerra Campos}

Programa de Pós-Graduação em Engenharia Civil e Ambiental | Universidade Federal da Paraíba | Campus I, Cidade Universitária, Castelo Branco | João Pessoa - PB - Brasil | CEP 58051-900 | E-mail: camposc873@gmail.com

\section{José Augusto Ribeiro da Silveira}

Programa de Pós-Graduação em Engenharia Civil e Ambiental | Universidade Federal da Paraíba | Tel.: (83) 3216-7200 | E-mail:

ct.laurbe@gmail.com

\section{Geovany Jessé Alexandre da Silva}

Programa de Pós-Graduacão em Engenharia Civil e Ambiental | Universidade Federal da Paraíba | Caixa Postal 92 | CEP 58051-970 | Tel.: (83) 3216-7200 | E-mail: alexarq.ufpb@gmail.com

\section{Eduardo Rodrigues Viana de Lima}

Centro de Ciências Exatas e da Natureza, Departamento de Geociências | Universidade Federal da Paraíba | Cidade Universitária, Castelo Branco III | João Pessoa - PB -Brasil | CEP 58059-900 | Tel.: (83) 3216-7432 | E-mail: eduvianalima@gmail.com

\section{Mauro Normando Macêdo Barros Filho}

Programa de Pós-Graduação em Engenharia Civil e Ambiental | Universidade Federal de Campina Grande | Rua Aprígio Veloso, 882, Universitário | Campina Grande - PB - Brasil | CEP 58429-140 | Tel.: (83) 2101-1773 | E-mail: mbarrosfilho@gmail.com

\section{Niara Fernandes Barbosa Formiga Dantas}

Programa de Pós-Graduação em Arquitetura e Urbanismo | Universidade Federal da Paraíba | E-mail: niaraformiga@gmail.com

\section{Ambiente Construído}

Revista da Associação Nacional de Tecnologia do Ambiente Construído

Av. Osvaldo Aranha, $99-3^{\circ}$ andar, Centro

Porto Alegre - RS - Brasil

CEP $90035-190$

Telefone: +55 (51) 3308-4084

www.seer.ufrgs.br/ambienteconstruido

www.scielo.br/ac

E-mail: ambienteconstruido@ufrgs.br 